\title{
A New Measure of Herding and Empirical Evidence
}

Soosung Hwang and Mark Salmon 


\title{
A New Measure of Herding and Empirical Evidence
}

\author{
Soosung Hwang ${ }^{1}$ \\ Faculty of Finance, \\ City University Business School \\ Mark Salmon \\ Faculty of Finance, \\ City University Business School
}

November 2001

\footnotetext{
${ }^{1}$ Faculty of Finance, City University Business School, Frobisher Crescent, Barbican Centre, London EC2Y 8HB, UK. Tel) +44 (0)20 7477 0109, Fax) +44 (0)20 74778881 , Email) s.hwang@city.ac.uk. We would like to thank Gordon Gemmill and Steve Satchell for their helpful comments.
} 


\begin{abstract}
This study proposes a new measure and test of herding which is based on the crosssectional dispersion of factor sensitivity of assets within a given market. This new measure enables us to evaluate the directions towards which the market may be herding and separate these from movements in fundamentals. We apply the test to an analysis of the US, UK, and South Korean stock markets and somewhat surprisingly, find statistically significant evidence of herding towards "the market portfolio" during relatively quiet periods rather than when the market is under stress. The approach also allows us to investigate herding towards other factors beyond the market factor and we find that the US market shows significant herding towards "value" after the Russian Crisis in 1998.
\end{abstract}

Keyword Herding, Non-central Chi Square Distribution, Cross-sectional Volatility, Risk Management.

JEL Code C12,C31,G12,G14 


\section{Introduction}

Herding arises when investors decide to imitate the observed decisions of others in the market rather than follow their own beliefs and information. Such behaviour may be seen to be individually rational on a number of grounds although it may not necessarily lead to efficient market outcomes. Herding can be rational in a utilitymaximising sense, for instance, if the other participants in the market are thought to be better-informed or if deviating from the consensus is potentially costly as, for example, in the remuneration of fund managers ${ }^{1}$. The suppression of private information can lead to "information cascades" in which the market price reflects less and less new information as new members of the herd are recruited- a process which moves the market towards inefficiency, see Banerjee (1992). This form of correlated behaviour can be in principle separated from what Bikhchandani and Sharma (2000) refer to as "spurious" or unintentional herding where independent individuals decide to take similar actions induced by the movement of fundamentals ${ }^{2}$.

Leaving aside issues of what may be rational or irrational motives for herding it is clearly important to be able to discriminate empirically between these two cases of common or correlated movements in the market; one of which potentially leads to market inefficiency whereas the other simply reflects an efficient reallocation of assets on the basis of common fundamental news. Since both motivations represent collective movements in the market towards some position or view and hence some class of assets it has not been easy to develop statistical methods that discriminate between these two cases and that is the principal objective of this paper.

Several measures have been developed to investigate herd behaviour in financial markets. Lakonishok, Shleifer, and Vishny (1992) (LSV) based their criterion on the trades conducted by a subset of market participants over a period of time. However, this measure critically does not account for the quantity of stock investors buy or sell. Wermers (1995) proposed a portfolio-change measure (PCM) which is designed to capture both the direction and intensity of trading by investors. A third method proposed by Christie and Huang (1995) investigates the magnitude of cross-sectional dispersion (or volatility) of individual stock returns during large price changes. If the dispersion is small during the large price changes then they suggest that there

\footnotetext{
${ }^{1}$ See Banerjee (1992), Bikhchandani, Hirshleifer, and Welch (1992), and Welch (1992) for information-based herding, Scharfstein and Stein (1990) reputation-based herding, and for compensation-based herding Brennan (1993), and Roll (1992). These studies on herd behaviour are closely related to the study of contagion, see Eichengreen, Mathieson, Chadha, Jansen, Kodres and Sharma (1998) for example.

${ }^{2}$ The terminology in this area can be difficult and unintuitive. We will, in what follows, try to retain simplicity and use the term herding in its common pejorative sense when it implies the suppression of private information and imitation without reference to fundamentals. The independent collective actions rationally following fundamental signals we will refer to simply as correlated fundamentals adjustment in the market or fundamental herding.
} 
is evidence of herding. However, by focussing on the variance of returns severely limits the value of the $\mathrm{CH}$ measure, since cross-sectional volatility on returns is not independent of time series volatility of returns and thus may not be used directly to investigate herd behaviour ${ }^{3}$.

In this paper, we develop a new measure of herding using linear factor models in which we can condition on observed movements in fundamentals. The measure is similar to the method of Christie and Huang (1995) (CH) only in that we exploit the information held in the cross-sectional movements of the market. However, we focus on the cross-sectional variability of factor sensitivities rather than returns themselves. Moreover we develop an explicit statistical testing procedure for herding based on our measure. The measure is relatively easy to calculate since it is based on returns data, whilst the LSV and PCM measures need records of detailed trading activities and information on changes in portfolios which in many cases may not be available. We therefore measure market-wide herding rather than herding by a group of investors.

Our measure uses the cross-sectional standard deviation of the factor loadings of the individual assets in a linear factor model. For a one factor model where the factor is market returns, the measure of herding is simply calculated from the individual betas. When there is herding "toward the market portfolio" the crosssectional variance of the estimated betas will decrease. The use of linear factor models can also provide additional insights into the directions of herd behaviour based on different factors beyond the market factor such as growth and value factors.

Unlike the $\mathrm{CH}$ measure, we automatically control for information on fundamentals by focussing on the cross-sectional movement in the betas rather than the factor returns themselves. Thus our measure reflects intentional herding and not the correlated adjustment to fundamentals. The measure also automatically takes account of the effects of changes in the time series volatility which are included in the crosssectional variance.

Chang, Cheng and Khorana (2000) have recently suggested a variant of the $\mathrm{CH}$ method. They show that under CAPM assumptions, rational asset pricing models suggest that the equity return dispersion, measured by the cross-sectional absolute deviation of returns, should be a linear function of market returns. Using US, Hong Kong, Japan, South Korea, and Taiwan market data, they find evidence of herding in South Korea and Taiwan. However, the measure developed by Chang, Cheng and Khorana (2000) neither considers the time-varying properties of beta in the CAPM nor herding towards other factors which might be important in the explanation of asset returns.

Throughout this study we implicitly assume that herding should naturally be

\footnotetext{
${ }^{3}$ See Hwang (2000) for the analytical and empirical relationship between cross-sectional volatility and time series volatility.
} 
viewed in a relative sense rather than as an absolute. We believe that no market will ever be completely free of herding. Thus we argue that there is either more or less herding in a market at some particular time compared to another and so herding is a matter of degree. We can also, given the statistical framework below, formally test whether herding differs significantly at one time from another. It seems to us conceptually difficult if not impossible to rigorously define a statistic which could provide an absolute measure of herding. However, we note that most herd measures that have been proposed, such as LSV, PCM, CH and Chang, Cheng and Khorana (2000), have apparently tried to identify herding in absolute terms.

In the next section we develop the proposed measure based on the cross-sectional standard deviation of the betas in a linear factor model. Under standard assumptions and using the OLS estimator we show that it follows a non-central Chi square distribution. In section 3, we apply the new measure to the US, UK, and South Korean stock markets. We find, with a result that may be initially surprising, that herding toward the market portfolio arises during relatively quiet periods rather than when the markets are under stress. That is, for the South Korean market, we find evidence of herding towards the market portfolio before the Asian Crisis in 1997 whilst for the US and UK markets, herding towards the market portfolio is observed before the Russian Crisis in 1998. When we consider market, growth, value and size factors together, we find evidence that the US market shows herding toward value rather than growth after the Russian Crisis in 1998 which can be easily explained with risk averse investors.

\section{A New Measure and Test of Herding}

In Christie and Huang (1995), the cross-sectional standard deviation of individual stock returns is calculated and then regressed on a constant and two dummy variables designed to capture extreme positive and negative market returns. They argue that during market stress rational asset pricing would imply positive coefficients on these dummy variables, whilst herd behaviour would suggest negative coefficients. However, market stress does not necessary imply that the market as a whole should show either large negative or positive returns. For example, we have recently seen periods of large swings in both the Dow Jones and the NASDAQ (or the old and new economies) whilst the market for stocks as a whole has not shown any dramatic change in the aggregate. In this case, without any large movement in the whole market we may still observe considerable reallocation towards particular sectors. Thus, defining herding as only arising when there are large positive or negative returns will exclude these important examples of herd behaviour and regressing the crosssectional volatility of returns on the two dummy variables will result in misleading conclusions. In addition, the introduction of dummy variables is itself crude since 
the choice of what is meant by "extreme" is entirely subjective. Moreover since the method does not include any device to control for movements in fundamentals it is impossible to conclude whether it is herding or independent fundamental adjustment that is taking place, and therefore whether or not the market is moving towards a relatively efficient or an inefficient direction.

Another problem with using the simple cross-sectional standard deviation of individual stock returns as in $\mathrm{CH}$ is that it is not independent of time series volatility. Hwang (2000) shows that cross-sectional volatility and time series volatility are theoretically and empirically significantly positively correlated and therefore, the uncertainty of return predictability decreases with cross-sectional volatility. Hence even if we find a small cross-sectional volatility of returns we cannot be sure whether it originates from a decreased uncertainty about the future or herding.

\section{A. Linear Factor Model and Some Cross-sectional Results}

Suppose that the excess return $r_{i t}$ of asset $i$ follows the linear factor model;

$$
r_{i t}=\alpha_{i t}+\beta_{i m t} r_{m t}+\sum_{k=1}^{K} \beta_{i k t} f_{k t}+\varepsilon_{i t}, i=1, \ldots, N \text { and } t=1, \ldots, T,
$$

where $\alpha_{i t}$ is a constant that changes over time, $\beta_{i m t}$ and $\beta_{i k t}$ are the coefficients on the excess market portfolio return and factor $k$ at time $t$, and $r_{m t}$ and $f_{k t}$ are the excess market portfolio return and the realised value of factor $k$ at time $t$. As in conventional linear factor models, we assume that the explanatory variables, $r_{m t}$ and $f_{k t}$ are uncorrelated.

Note that the linear factor model we use does not require that the market is in equilibrium or efficient. The factors in equation (1) may be risk factors or account for anomalies. For instance, the factors can correspond to countries, industries, currencies, styles, macroeconomic variables, or other persistent anomalies.

We need to define the cross-sectional expectation.

Definition 1 Let the market investment weight on asset $i$ at time $t$ be denoted by $w_{i t}$. This weight is a probability measure, since $w_{i t} \geq 0$ for all $i$ and $t$, and $\sum_{i=1}^{N} w_{i t}=1$ for all $t$. Therefore, for any variable $x_{i t}$, we can define

$$
E_{C}\left(x_{i t}\right)=\sum_{i=1}^{N} w_{i t} x_{i t}
$$

Cross-sectional expectations can therefore be thought of as taking expectations with respect to a measure where the weights are determined by the market. 
We can now calculate the cross-sectional mean and volatility for asset returns at time $t$. The market portfolio return at time $t$ is a cross-sectional expected value of all individual asset returns at time $t$;

$$
\begin{aligned}
r_{m t} & =E_{C}\left[r_{i t}\right] \\
& =E_{C}\left[\alpha_{i t}+\beta_{i m t} r_{m t}+\sum_{k=1}^{K} \beta_{i k t} f_{k t}+\varepsilon_{i t}\right] \\
& =E_{C}\left[\alpha_{i t}\right]+r_{m t} E_{C}\left[\beta_{i m t}\right]+\sum_{k=1}^{K} f_{k t} E_{C}\left[\beta_{i k t}\right]+E_{C}\left[\varepsilon_{i t}\right],
\end{aligned}
$$

where $E_{C}[$.$] represents the cross-sectional expectation given in (2).$

Proposition 2 For the linear factor model in (1), we have

$$
\begin{aligned}
E_{C}\left[\alpha_{i t}\right] & =0, \\
E_{C}\left[\beta_{i m t}\right] & =1, \\
E_{C}\left[\beta_{i k t}\right] & =0, \forall k, \\
E_{C}\left[\varepsilon_{i t}\right] & =0 .
\end{aligned}
$$

Proof. A simple way to see the above results is to regress $r_{m t}$ on a constant, $r_{m t}$, and $f_{k t}, k=1, \ldots, K$ and use the fact that $r_{m t}$ and $f_{k t}$ are not correlated.

The four conditions in (4) show that in terms of cross-sectional analysis, the averaged value of betas on the market portfolio is unity, but the averaged values of the other coefficients are zero. This is useful when we calculate cross-sectional statistics, since the cross-sectional variance can now be calculated easily with the means in (4).

Given (4), the cross-sectional volatility of $r_{i t}$ at time $t, \operatorname{var}_{C}\left(r_{i t}\right)$, is

$$
\begin{aligned}
\operatorname{var}_{C}\left(r_{i t}\right) & =E_{C}\left[\left(r_{i t}-r_{m t}\right)^{2}\right] \\
& =E_{C}\left[\alpha_{i t}^{2}\right]+r_{m t}^{2} E_{C}\left[\left(\beta_{i m t}-1\right)^{2}\right]+\sum_{k=1}^{K} f_{k t}^{2} E_{C}\left[\beta_{i k t}^{2}\right]+E_{C}\left[\varepsilon_{i t}^{2}\right]+\operatorname{Cov}_{C t} \\
& =\operatorname{var}_{C}\left(\alpha_{i t}\right)+r_{m t}^{2} \operatorname{var}_{C}\left(\beta_{i m t}\right)+\sum_{k=1}^{K} f_{k t}^{2} \operatorname{var}_{C}\left(\beta_{i k t}\right)+\operatorname{var}_{C}\left(\varepsilon_{i t}\right)+\operatorname{Cov}_{C t}
\end{aligned}
$$

where $\operatorname{Cov}_{C t}$ is sum of the expected cross-products, $\operatorname{var}_{C}\left(\alpha_{i t}\right) \equiv E_{C}\left[\alpha_{i t}^{2}\right], \operatorname{var}_{C}\left(\beta_{i m t}\right) \equiv$ $E_{C}\left[\left(\beta_{i m t}-1\right)^{2}\right], \operatorname{var}_{C}\left(\beta_{i k t}\right) \equiv E_{C}\left[\beta_{i k t}^{2}\right], \operatorname{var}_{C}\left(\varepsilon_{i t}\right) \equiv E_{C}\left[\varepsilon_{i t}^{2}\right]$. Note that $\operatorname{var}_{C}($.$) repre-$ sents cross-sectional variance and $\operatorname{var}_{C}\left(\varepsilon_{i t}\right) \rightarrow 0$ as $N \rightarrow \infty$ under weak assumptions of the boundedness of $E_{C}\left[\varepsilon_{i t}^{2}\right]$. In addition, the cross-sectional covariance, $\operatorname{Cov}_{C t}$, 
becomes zero if we assume that $\alpha_{i t}, \beta_{i m t}, \beta_{i k t}$, and $\varepsilon_{i t}$ are cross-sectionally uncorrelated. See Hwang (2000) for a more detailed explanation of the cross-sectional properties of linear factor models.

\section{B. A New Measure of Herding}

We now introduce the new measure of herding given the cross-sectional variance of the factor loadings of the individual assets in (5). ${ }^{4}$ The critical argument underlying our approach is the following; the linear factor model in (1) suggests that herding toward the market portfolio will be shown by a reduction in the cross sectional dispersion of the beta on the market portfolio, $\beta_{i m t}$. For example, if at any given time more investors adopt strategies that imitate the general market movement then the cross-sectional dispersion of $\beta_{i m t}$ should become smaller than when there is no herding. Since the cross-sectional volatility of $r_{i t}, \operatorname{var}_{C}\left(r_{i t}\right)$, removes the effects of heteroskedastic market returns, $r_{m t}^{2}$, the measure is robust, through conditioning, against the effects of volatile market movements. This implies that our measure does not depend upon the time series volatility of the market returns, but depends simply on any changes in the relationships between individual stock returns and the market return.

The presence of such behaviour implies that the market is not fully efficient and this is of course one of the main reasons why we are interested in detecting herding as opposed to correlated fundamental adjustments which would not affect the cross-sectional dispersion. Note that beta, $\beta_{i m t}$, represents systematic risk and that changes of beta over time have often been explained by financial leverage ( see Black (1976) and Christie (1982)). Cho and Engle (1999) find evidence that both idiosyncratic and market news increase betas if it represents bad news and decreases betas in the case of good news. Using their results, we can explain why our measure of herding is robust to apparent herding through correlated fundamental adjustments based on rational decision making and thus the measure captures the imitative concept of herding we seek to measure.

Firstly, the effects of idiosyncratic news on the cross-sectional statistics of individual betas should be slight; the cross-sectional average and variance of the changed betas are expected to remain unchanged, since the effects of idiosyncratic news will become insignificant in the average. ${ }^{5}$ On the other hand, since market wide news is common for all assets we would expect individual betas to move in unison relative

\footnotetext{
${ }^{4}$ In this study, we use the cross-sectional variance of $b_{i m t}\left(\right.$ or $b_{i k^{*} t}$ ) as a measure of herding for the factor. In more general cases, we could use Gini's mean difference introduced in finance by Yitzhaki (1982) and Shalit and Yitzhaki (1984).

${ }^{5}$ This is similar to the argument with which Connor (1984) explained an approximate arbitrage pricing model.
} 
to the market, either up or down depending on whether it is good or bad news. Individual returns may well diverge but given the assumptions of the model there is no reason why the cross-sectional variance of the betas should change. In the cross-sectional world, the relationship in (4) is always true so we would not expect the cross-sectional dispersion to be changed significantly over time by market wide news. Therefore, in the cross-section, the degree of dispersion of the individual betas is not expected to change significantly over time in response to either idiosyncratic or fundamental news. So any rapid or significant changes in the cross-sectional variance of the beta coefficients and hence our measures will indicate herding and not collective actions following fundamental news. Any rapid changes in the factor loadings, as opposed to changes in the factor values which would occur naturally, indicate movements relative to the factors and hence herding in specific directions.

Using the linear factor model in (1) we can measure potential herding towards other factors in addition to herding towards the market factor. For example, herding toward some factor $k$ can be measured with the cross-sectional variance of the coefficient $\beta_{i k t}$. Using this approach, we can therefore investigate if there has been herding towards developed or emerging market stocks for instance. We therefore define measures of herding toward the market and toward some factor as follows;

Definition 3 Herding "towards the market portfolio", $H(m, t)^{*}$, is defined as a reduction in

$$
H(m, t)^{*}=\operatorname{var}_{c}\left(\beta_{i m t}\right),
$$

and herding toward factor $k^{*}, H\left(k^{*}, t\right)$, is defined as an increase in

$$
H\left(k^{*}, t\right)^{*}=\operatorname{var}_{C}\left(\beta_{i k^{*} t}\right) .
$$

When $H(m, t)^{*}$ increases, many of the individual $\beta_{i m t}$ become significantly different from one. This means that individual stock returns scatter more widely around the market return, suggesting less conformity and hence herding and vice versa. On the other hand, when $H\left(k^{*}, t\right)^{*}$ increases, many $\beta_{i k^{*} t}$ become significantly different from zero. Since the cross-sectional mean of the coefficients on the other factors is always zero, we cannot expect all the coefficients of the individual stocks to be positive (or negative). For example, for some stocks, the coefficients on the size factor may become significantly negative, but for other stocks, they may become significantly positive. Any significant deviation of the coefficients from zero represents herding towards the factors and significant herding towards a factor at time $t$ is summarised by a large value of $H\left(k^{*}, t\right)^{*}$.

As mentioned above, these definitions do not provide absolute measures of herding. As the criteria change over time, we observe relatively more or less herding behaviour in the market. 


\section{The Test of Herding}

The critical issue is whether an increase or decrease in herding at some time is statistically significant or not. For this we develop the statistical properties of the criteria above using the OLS estimator because of analytic convenience.

The time-varying betas in (1) are difficult to estimate unless we use some additional information as in Ferson and Harvey (1995). As widely accepted in practice, we assume that the betas are constant over a fixed interval $\tau$, but change slowly over time. When $\tau$ is very large, we will fail to capture the time variation in the regression coefficients, whilst when $\tau$ is too small, the OLS estimator becomes inefficient. In general, 5 to 7 years is used for $\tau$ for monthly returns, i.e., 60 to 84 monthly observations.

Using $\tau$ observations, we can write

$$
\mathbf{r}_{i t}=\mathbf{X}_{t} \boldsymbol{\beta}_{i t}+\varepsilon_{i t}
$$

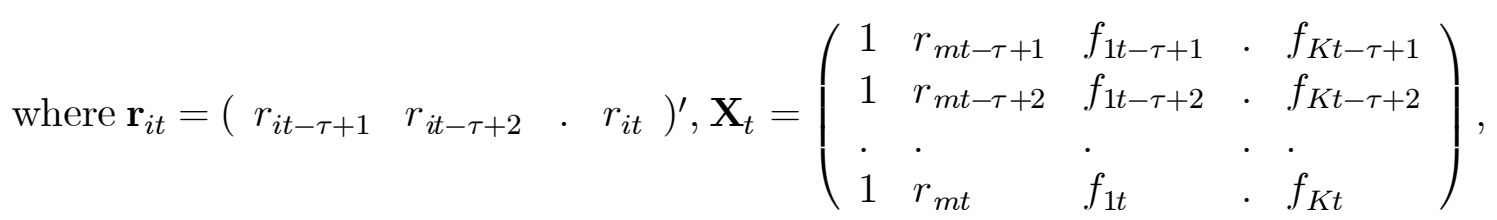
$\boldsymbol{\beta}_{i t}=\left(\begin{array}{lllll}\alpha_{i t} & \beta_{i m t} & \beta_{i 1 t} & . & \beta_{i K t}\end{array}\right)^{\prime}$, and $\boldsymbol{\varepsilon}_{i t}=\left(\begin{array}{llll}\varepsilon_{i t-\tau+1} & \varepsilon_{i t-\tau+2} & . & \varepsilon_{i t}\end{array}\right)^{\prime}$.

For all $N$ assets in the market, we can stack the $N$ equity returns to make a Seemingly Unrelated Regression (SUR) model. However, since the explanatory variables are the same for all $N$ equities, the SUR estimator is identical to the OLS estimator applied to each individual equity and hence we gain a fully efficient estimator using OLS. The OLS estimator for asset $i$ at time $t$ is then simply

$$
\begin{aligned}
\mathbf{b}_{i t} & =\left(\mathbf{X}_{t}^{\prime} \mathbf{X}_{t}\right)^{-1} \mathbf{X}_{t}^{\prime} \mathbf{r}_{i t} \\
\operatorname{var}\left(\mathbf{b}_{i t}\right) & =\sigma_{i}^{2}\left(\mathbf{X}_{t}^{\prime} \mathbf{X}_{t}\right)^{-1}
\end{aligned}
$$

where $\sigma_{i}^{2}=E\left(\varepsilon_{i t}^{2}\right)$ which can be estimated with $s_{i}^{2}=\frac{1}{\tau-K-2} \sum e_{i t}^{2}$ and $e_{i t}$ is the OLS residual. Let $S^{m}$ (or $S^{k}$ ) be the diagonal element of $\left(\mathbf{X}_{t}^{\prime} \mathbf{X}_{t}\right)^{-1}$ for the market beta (or factor $k$ ).

One problem with the OLS estimator is that some large insignificant estimates of $b_{i m t}$ (or $b_{i k^{*} t}$ ) from one (or zero) may have significant effects on the magnitudes of the cross-sectional dispersion of $b_{i m t}\left(\right.$ or $\left.b_{i k^{*} t}\right)$. In this case, we might conclude erroneously that there is no evidence of herding towards the market (or alternatively evidence of herding toward the specific factor). However, since these deviations from one (or zero) are statistically insignificant, the large cross-sectional dispersion does not necessarily provide information about herd behaviour. To avoid this difficulty, we standardise $b_{i m t}\left(\right.$ or $b_{i k^{*} t}$ ) with its own sample standard deviation. 
Definition 4 The measure of herding towards the market portfolio is

$$
H(m, t)=\operatorname{var}_{c}\left(\frac{b_{i m t}-1}{\sqrt{s_{i}^{2} S^{m}}}\right),
$$

and the measure of herding toward factor $k^{*} i s$

$$
H\left(k^{*}, t\right)=\operatorname{var}_{c}\left(\frac{b_{i k^{*} t}}{\sqrt{s_{i}^{2} S^{k^{*}}}}\right),
$$

where $b_{i m t}$ and $b_{i k^{*} t}$ are the OLS estimates for the market portfolio and factor $k^{*}$ for stock $i$ at time $t$, and $s_{i}^{2}$ and $S^{m}$ are defined in equations (9) and (10).

These measures can be calculated easily from any standard estimation program since they are given by the cross-sectional variance of the $t$ statistics of the estimated factor loadings.

We now turn to investigate the statistical properties of the new measures in (11) and (12) and develop the test procedure. The OLS estimator shows that $b_{\text {imt }} \sim$ $N\left(\beta_{i m t}, \sigma_{i}^{2} S^{m}\right)$, or $b_{i m t}-1 \sim N\left(\beta_{i m t}-1, \sigma_{i}^{2} S^{m}\right)$ for the beta on the market return and $b_{i k t} \sim N\left(\beta_{i k t}, \sigma_{i}^{2} S^{k}\right)$ for the beta on factor $k$. Using these properties of the OLS estimator, we have the following theorem.

Theorem 5 The herding measure for the market portfolio obeys the following distribution

$$
\begin{aligned}
H(m, t) & =\frac{1}{N} \sum_{i=1}^{N} \frac{\left(b_{i m t}-1\right)^{2}}{s_{i}^{2} S^{m}} \\
& \sim \frac{1}{N} \sum_{i=1}^{N} F\left(1, \tau-K-2 ; \frac{\left(\beta_{i m t}-1\right)^{2}}{\sigma_{i}^{2} S^{m}}\right)
\end{aligned}
$$

where $\frac{\left(\beta_{i m+}-1\right)^{2}}{\sigma_{i}^{2} S^{m}}$ is the non-centrality parameter of the $F$ distribution for asset $i$. On the other hand, for the other factors, $k^{*}$, the herd measure follows

$$
\begin{aligned}
H\left(k^{*}, t\right) & =\frac{1}{N} \sum_{i=1}^{N} \frac{b_{i k^{*} t}^{2}}{s_{i}^{2} S^{k^{*}}} \\
& \sim \frac{1}{N} \sum_{i=1}^{N} F\left(1, \tau-K-2 ; \frac{\beta_{i k^{*} t}^{2}}{\sigma_{i}^{2} S^{k^{*}}}\right)
\end{aligned}
$$

where $\frac{\beta_{k^{*}+}^{2}}{\sigma_{i}^{2} S^{* *}}$ is the non-centrality parameter of $F$ distribution for asset $i$. 
Proof. Since $b_{i m t}-1 \sim N\left(\beta_{i m t}-1, \sigma_{i}^{2} S^{m}\right)$,

$$
\frac{\left(b_{i m t}-1\right)^{2}}{\sigma_{i}^{2} S^{m}} \sim \chi^{2}\left(1 ; \frac{\left(\beta_{i m t}-1\right)^{2}}{\sigma_{i}^{2} S^{m}}\right),
$$

where $\frac{\left(\beta_{i m+}-1\right)^{2}}{\sigma_{i}^{2} S^{m}}$ is the non-centrality parameter. In addition, we have the following relationship between the OLS estimator $s_{i}^{2}$ and the true $\sigma_{i}^{2}$

$$
\frac{(\tau-K-2) s_{i}^{2}}{\sigma_{i}^{2}} \sim \chi^{2}(\tau-K-2) .
$$

Thus, we obtain

$$
\frac{\left(b_{i m t}-1\right)^{2}}{s_{i}^{2} S^{m}} \sim F\left(1, \tau-K-2 ; \frac{\left(\beta_{i m t}-1\right)^{2}}{\sigma_{i}^{2} S^{m}}\right) .
$$

Therefore, the herd measure can be shown to follow

$$
\frac{1}{N} \sum_{i=1}^{N} \frac{\left(b_{i m t}-1\right)^{2}}{s_{i}^{2} S^{m}} \sim \frac{1}{N} \sum_{i=1}^{N} F\left(1, \tau-K-2 ; \frac{\left(\beta_{i m t}-1\right)^{2}}{\sigma_{i}^{2} S^{m}}\right) .
$$

For the other factors, since the cross-sectional mean is zero, the herd measure in (14) can be easily obtained using the same method as above.

The above theorem shows that our new measures of herding are distributed as the mean of $N$ non-central $F$ distributions with different non-centrality parameters $\left(\beta_{i m t}-1\right)^{2} / \sigma_{i}^{2} S^{m}$ and with degrees of freedom 1 for the numerator and $\tau-K-2$ for the denominator ${ }^{6}$. The herd measure for the factor $k^{*}$ can be explained in a similar way.

Tests using the mean of $F$ distributions need a series of simulations to tabulate the test statistics, which is cumbersome. When $\tau-K-2$ becomes large, we can however simplify the mean of the non-central $F$ distributions into non-central $\chi^{2}$ distributions as in the following corollary.

Corollary 6 For large $\tau-K-2$, the mean of non-central distributions in (13) becomes

$$
\frac{1}{N} \sum_{i=1}^{N} \frac{\left(b_{i m t}-1\right)^{2}}{s_{i}^{2} S^{m}} \sim \frac{1}{N} \chi^{2}\left(N ; \delta_{m}\right),
$$

\footnotetext{
${ }^{6}$ The properties of the mean of non-central $F$ distributions were explored recently by Hwang and Satchell (2000) to test linear factor models. They showed that the mean of $F$ distributions has more power than the conventional $F$ tests in the presence of missing factors. They also tabulated the test statistics for the mean of $F$ distributions for some critical values using simulations since analytical analysis based on the mean of $F$ distributions is difficult. See Hwang and Satchell (2000) and Campbell, Lo, and MacKinlay (1997) for the test with the mean of $F$ distributions and the conventional $F$ tests in the linear factor model, respectively.
} 
where $\delta_{m}$ is the non-centrality parameter, i.e., $\delta_{m}=\sum_{i=1}^{N} \frac{\left(\beta_{i m+}-1\right)^{2}}{\sigma_{i}^{2} S^{m}}$. For factor $k^{*}$, with large $\tau-K-2$, we have

$$
\frac{1}{N} \sum_{i=1}^{N} \frac{b_{i k^{*} t}^{2}}{s_{i}^{2} S^{k^{*}}} \sim \frac{1}{N} \chi^{2}\left(N ; \delta_{k^{*}}\right)
$$

where $\delta_{k}$ is the non-centrality parameter, i.e., $\delta_{k^{*}}=\sum_{i=1}^{N} \frac{\beta_{i k^{*}}^{2}}{\sigma_{i}^{2} S^{k^{*}}}$.

The true $\beta_{i m t}$ or $\beta_{i k t}$ included in the non-centrality parameters, $\delta_{m}$ and $\delta_{k^{*}}$, can be replaced by the OLS estimator when $N$ is large as follows

Corollary 7 When $N$ is sufficiently large, $\widehat{\delta}_{m} \approx \delta_{m}+N$ and $\widehat{\delta}_{k^{*}} \approx \delta_{k^{*}}+N$. This means that for large $N$, we have

$$
\begin{aligned}
& H(m, t)=\frac{1}{N} \sum_{i=1}^{N}\left(b_{i m t}-1\right)^{2} \sim \chi^{2}\left(N ; \widehat{\delta}_{m}-N\right), \\
& H\left(k^{*}, t\right)=\frac{1}{N} \sum_{i=1}^{N} b_{i k^{*} t}^{2} \sim \chi^{2}\left(N ; \widehat{\delta}_{k^{*}}-N\right),
\end{aligned}
$$

where $\widehat{\delta}_{m}=\sum_{i=1}^{N} \frac{\left(b_{i m t}-1\right)^{2}}{\sigma_{i}^{2} S^{m}}$ and $\widehat{\delta}_{k^{*}}=\sum_{i=1}^{N} \frac{b_{i k^{*}}^{2}}{\sigma_{i}^{2} S^{k^{*}}}$.

Proof. Suppose that the relationship between OLS estimator and the true parameter can be represented as $b_{i m t}=\beta_{i m t}+\eta_{i m t}$, where $\eta_{i m t} \sim N\left(0, \sigma_{i}^{2} S^{m}\right)$ from equations (9) and (10). When we define $\widehat{\delta}_{m}$ as the non-centrality parameter calculated from OLS estimator $b_{i m t}$, we have

$$
\begin{aligned}
\widehat{\delta}_{m} & =\sum_{i=1}^{N} \frac{\left(b_{i m t}-1\right)^{2}}{\sigma_{i}^{2} S^{m}} \\
& =\sum_{i=1}^{N} \frac{\left(\beta_{i m t}-1+\eta_{i m t}\right)^{2}}{\sigma_{i}^{2} S^{m}} \\
& =\sum_{i=1}^{N} \frac{\left(\beta_{i m t}-1\right)^{2}}{\sigma_{i}^{2} S^{m}}+\sum_{i=1}^{N} \frac{\eta_{i m t}^{2}}{\sigma_{i}^{2} S^{m}} \\
& =\sum_{i=1}^{N} \frac{\left(\beta_{i m t}-1\right)^{2}}{\sigma_{i}^{2} S^{m}}+\chi^{2}(N),
\end{aligned}
$$

since $\sum_{i=1}^{N} \frac{\left(\beta_{i m t}-1\right) \eta_{i m t}}{\sigma_{i}^{2} S^{m}}=0$ for large $N$ and $\eta_{i m t}^{2}=\chi^{2}(1) \sigma_{i}^{2} S^{m}$. With the same method, the non-centrality parameter calculated from OLS estimator $b_{i k^{*} t}, \widehat{\delta}_{k^{*}}$, is $\widehat{\delta}_{k^{*}}=\sum_{i=1}^{N} \frac{\beta_{i k_{*}^{*}+}^{2}}{\sigma_{i}^{2} S^{k^{*}}}+\chi^{2}(N)$. 


\section{The Test Procedure}

The test statistics enable us to determine in a recursive manner whether the degree of herding has increased or decreased significantly over time. Using equations (11) and (12), we first calculate the test statistic at time $t$ with an appropriate choice of $\tau$. Their confidence intervals can be obtained from equation (18). The same procedure is then repeated over time by advancing the start date by one period, i.e., $t, t+1, \ldots$

The recursively generated test statistics together with their confidence interval provide us with, in effect, a sequence of hypothesis tests. That is, we can use the confidence level calculated at time $t$ to test if the value of the test statistic at $t+1$ changes significantly. In this way we can determine if the level of herding is significantly different over time. If we set one fixed level of herding from which we wish to determine deviations, we could also test absolute herding relative to that subjective benchmark herding level. However that would be dependent on a subjective choice of the benchmark herding level.

The new criteria in (11) and (12) allow us to remove the effects of volatility defined over time, take account of other important factors through conditioning, and provide us with test statistics based on our measures of herding as shown in (18). In Christie and Huang (1995) there is no statistical method available to decide if the cross-sectional return volatility is significantly "large" or "small". Finally, our new herd measure can provide a tool for measuring herding towards styles (factors), which is not possible with the cross-sectional variance of returns or the earlier measures again based on returns.

\section{Empirical Tests}

In this section, we use the measures developed above to investigate if there has been significant herding in the UK, US, and South Korean stock markets. The comparison of herding in advanced markets with that in an emerging market is interesting given their structural and institutional differences, see Bekaert, Erb, Harvey, and Viskanta (1997) for example, for an extensive discussion of what are the important factors in emerging markets.

We calculate the herd measures using the constituents of the S\&P500 index for the US market (500 stocks), those of the FTSE350 index for the UK market (350 stocks), and the KOPSI 200 index for the South Korean market (200 stocks). ${ }^{7}$ To be precise we use the constituents included in the indices as defined on the 29 November 2000 with a total number of 130 log-normal monthly returns from January 1990 to

\footnotetext{
${ }^{7}$ The KOSPI 200 index consists of major 200 stocks listed in the Korea Stock Exchange (KSE), making up close to $80 \%$ of market capitalization of the KSE. The KOSPI 200 is the underlying stock index for traded futures and options contracts on the KSE.
} 
October 2000. Due to changes in the structure of the indices and the non-existence of some equity returns in the early part of our sample, the number of equities at the beginning of the sample period is necessarily less than the number of constituents for each index. ${ }^{8}$

The market portfolio returns used are obtained by calculating equally weighted stock returns available at a given time. Technically, this is to ensure the conditions in (4) are satisfied, although we could have applied cap weights to calculate the market returns. Given constraints on data provision we can only use those stocks available in our data set implying that the market portfolio returns calculated are not exactly the same as the equally weighted market index returns. However, several experiments indicate that the market portfolio returns used in this study are sufficiently close to the real index returns to not impair our results.

We use three factors besides the market portfolio in the exercises below; growth, value, and size. Herding behaviour toward these three factors is analysed only for the US case again because of the limited availability of the factor data. For the other markets, we are able to use size for the South Korean market, but for the UK market we have not been able to construct any other factor apart from the market portfolio itself at present. ${ }^{9}$

\section{A. Factor Mimicking Portfolio}

In the analysis of linear factor models we need the factors themselves or their equilibrium risk premiums or a portfolio that mimics one or the other. Since the true factors are typically unobservable, there is no unambiguous route to obtaining the first two. However linear factor models with portfolios that mimic factors (factor mimicking portfolios) used as regressors are frequently used in models employed by more sophisticated practitioners.

A factor mimicking portfolio (FMP) is a portfolio of assets whose returns are designed to be highly correlated with the (unobservable) factor values. For instance, portfolios constructed from the eigenvectors in a principal component analysis are examples of factor mimicking portfolios. In this paper, we use the same method as in Hwang and Satchell (1999, 2000) and Hall, Hwang, and Satchell (2001) to construct factor mimicking portfolios as we now describe.

To calculate the FMPs in the US market, we use a total of 2046 US equities in the MSCI universe from January 1990 to March 1999. For each factor $f$, the universe is ranked by an attribute $f$. For instance, $f$ might be the size factor and

\footnotetext{
${ }^{8}$ When calculating excess returns, we use US and UK 3 month treasury bills and South Korean 1 year monetary stabilization bond.

${ }^{9}$ There are some UK factors available in the Datastream, but the time series are not long enough for our study. We guess that the UK results are not far different from those of the US.
} 
the universe of stocks would be ranked by their size attribute. Then an equally weighted portfolio is formed, that is, long the top $n$-tile ranked by the $f$ attribute, and short the bottom $n$-tile, ranked by the $f$ attribute. The resulting hedge portfolio is the factor mimicking portfolio of factor $f$. The order of the $n$-tile should typically be small and we use thirds $(n=3)$ in this study.

The three attributes used in this study are value (VL), growth (GR), and size (SZ), and the FMP calculated for the styles are factor mimicking portfolio for value (FVL), growth (FGR) and size (FSZ), respectively. Note that the returns of the FMPs are calculated each month. Thus, the number of equities used for the calculation of FMPs changes over time (but the maximum number is 2046). The values of the two attributes for each equity are defined as :

$$
\begin{aligned}
S Z_{t} & =\log (\text { SharePrice }(t) \times \text { ShareNumber }(t)), \\
V L_{t} & =\frac{D P_{t}+E P_{t}+S P_{t}+B P_{t}+C P_{t}}{5} \\
G R_{t} & =\frac{R E_{t}+E G_{t}}{2}
\end{aligned}
$$

where

$$
\begin{aligned}
D P_{t} & =\frac{\text { Dividend Per Share }(t)}{\text { Share Price }(t)}, \\
E P_{t} & =\frac{\text { Earnings Per Share }(t)}{\text { Share Price }(t)}, \\
S P_{t} & =\frac{\text { Net Sales Per Share }(t)}{\text { Share Price }(t)}, \\
B P_{t} & =\frac{\text { Book Value Per Share }(t)}{\text { Share Price }(t)}, \\
C P_{t} & =\frac{\text { Cash Flow Per Share }(t)}{\text { Share Price }(t)}, \\
R E_{t} & =\frac{\text { Earnings Per Share }(t)}{\text { Book Value Per Share }(t-12)}, \\
E G_{t} & =\log \left(\frac{\text { BookValue Per Share }(t)}{\text { Book Value Per Share }(t-24)}\right) .
\end{aligned}
$$

For the construction of the FMP for size in the South Korean Market, we use a slightly different method since the accounting information above is not available to us. We use the KSE classification for the size of companies, i.e., large, medium, and small. We first calculate equally weighted portfolio returns for large companies (227 in all) and for small companies (515 in all) which are classified as "large" and "small" groups in the Korea Stock Exchange (KSE) as of 29 November 1999. Then the FSZ 
returns are obtained by longing the portfolio returns of the smaller companies and shorting those of the larger companies. The constituents in each group changes over time and the classification rule has changed over time. However, we assume that the effects of these changes are not significant enough to change our results.

The above procedure can be seen to be a natural way to make the factor mimicking portfolios approximately uncorrelated. If the true factors are uncorrelated then sorting by the attributes and constructing long and short positions relative to factor 1, say, should produce a portfolio with little or no systematic exposure to factor 2. Actually, the attributes themselves may be strongly correlated and as a consequence, fully uncorrelated portfolios cannot be expected. However this procedure is preferable to using factor analysis or principal components since one usually loses any understanding of what the factors then signify.

Table 1 reports some statistical properties of the excess market returns and other factors in these markets. For the sample period, January 1990 to October 2000, we find that the excess returns for the two mature market portfolios (e.g., the US and UK markets) have similar properties; mean returns, standard deviations, negative skewness and positive excess kurtosis. However, during the same period, the Korean market shows a negative mean excess return with a high standard deviation. The South Korean market given the low return - high risk, would seem unattractive to foreign investors. However, the inclusion of an unattractive market can still expand the mean variance efficient frontier and can be considered an investable market in a global portfolio.

Another observation from table 1 is that the excess market returns are not normal; we find that most of the sample statistics for skewness and kurtosis in all three markets are significantly different from zero. Thus our assumption of normality may be too strong but serves as a first order approximation. In addition, none of the factor returns have mean returns significantly different from zero, suggesting that the FMPs (or hedge funds) do not produce significant positive or negative returns. Note that some correlation coefficients between FMPs in the US market are significant whilst market portfolio and FSZ are not correlated in the South Korean market. This may arise from the different procedures we used to calculate FSZ.

For the US market, we could use the factors suggested by Fama and French (1993). Hwang and Satchell (2000) used these Fama-French factors as well as the factors outlined above to calculate the value of information in the linear factor model of Fama and French (1993) and found little difference between the two sets. We believe that the empirical results in the next two sections would not be changed by using the Fama-French factors.

\section{B. Herding toward the Market Portfolio}


We first use the market model (one factor model) to investigate herding towards the market portfolio in the US, UK, and South Korean stock markets. As explained in above, we choose an appropriate number of monthly observations, i.e., $\tau$, to obtain the OLS estimate. In this study, we set $\tau=60,5$ years of monthly observations which is widely used in practice. Therefore for the market model, $\tau-K-2=58$ since $K=0$ (see equation (8)).

The procedure by which we calculated each herd measure is as follows. We use the first 60 observations up to December 1994 to obtain the $t$ statistics for each stock and then calculate the herd statistic for December 1994. We then add one observation at the end of the sample and drop the first and so use the next 60 observations up to January 1995 to obtain a statistic for January 1995, and so on. Given the absence of certain stocks in the early stages of our sample, the number of estimated regression coefficients is less than the total number of the constituents for each index, but the number increases steadily over time. For example, the first herd statistics (December 1994) for the US, UK, and South Korean stock markets are obtained with 410, 226, and 136 cross-sectional statistics, respectively.

Figures 1 to 3 show our new herd measures with the market indexes and the crosssectional standard deviations of stock returns over time for the three markets. ${ }^{10} \mathrm{We}$ also calculate and plot the upper and lower boundaries at 95\% confidence level calculated with (18) over time and the averaged value of the estimated herd statistics which is used here as the benchmark herding level.

The figures indicate several interesting patterns. The herd statistics clearly show that herding toward the market portfolio $(H(m, t))$ varies over time. For all three markets there are several significant sudden changes in $H(m, t)$ in the sense that these changes are far above or below the previous upper and lower boundaries at the $95 \%$ confidence level. Over the sample period there are also several periods when $H(m, t)$ is small, i.e., around two, whilst in other periods, $H(m, t)$ is very large, i.e, around four. This suggests that for some periods many of the estimated systematic risks may not be significantly different from one whilst for other periods, they seem to be significantly different from one.

Secondly, when we use the full sample average value of the estimated herding statistics as our absolute benchmark herding level, we find that the US market shows herding toward the market portfolio during a period from January 1996 to July 1998 and for the UK we see herding toward the market portfolio between June 1997 to September 1998. In both cases, small values of $H(m, t)$ were achieved when the markets were strongly bullish. The movement toward smaller values of $H(m, t)$ can actually be detected from the beginning of our sample period. Although there are some fluctuations over time, both the US and the UK markets show herding toward

\footnotetext{
${ }^{10}$ We arbitrarily put all the three indexes at 30 November 1994 equal to ten and then construct time series of the indexes to the end of sample period.
} 
the market portfolio during the bullish periods and the smallest $H(m, t)$ is obtained just before the Russian Crisis of 1998. After the Russian Crisis, the estimated value of $H(m, t)$ becomes larger and the market portfolio seems not to act as an attractor of investors' attentions and hence herding. For example, the estimated $H(m, t)$ after the Russian Crisis is nearly double when compared with that before the Crisis.

Further evidence of herding can be found in the South Korean Market during the relatively quiet period before the Asian Crisis of 1997. Figure 3 shows that before the Asian Crisis in the middle 1997 our herd statistics were significantly smaller than after the Crisis. Once again our herd statistics more than doubled by the end of 1997. Therefore, after the Crisis, the South Korean market did not herd towards the market portfolio.

Finally, the three figures also allow us to compare the relative degrees of herding towards the market portfolio across the three different markets. That is, when we compare quiet periods in the US and the South Korean Stock markets, the herd statistics for the South Korean market are usually between 1 and 2, whilst those of the US stock market are between 2 and 3. This means that the South Korean market shows more herding toward the market portfolio than the US market. The averaged values of the estimated herding statistics for the US, UK and South Korea markets, each of which are 3.4, 3.1, and 2.3 respectively, confirm the difference. Note that there is little difference between the US and UK markets. This is because the South Korean market as an emerging market, is more asymmetric in information than the advanced markets such as the US, and thus Korean investors may tend to follow the market movement more than US investors.

Our findings are not necessarily inconsistent with previous studies. We note that many empirical studies on herding in advanced markets find little concrete evidence of herd behaviour, see Bikhchandani and Sharma (2000). However, in the South Korean case, Kim and Wei (1999) and Choe, Kho, and Stulz (1999) studied herd behaviour around the Asian Crisis in 1997 and did find some evidence during the Crisis. Note that both these studies use the LSV measure which uses a subset of market participants. Therefore, we cannot conclude that their results are inconsistent with ours since our herd measure considers the whole market rather than a subset of participants. Recently Chang, Cheng and Khorana (2000), using a variant of the method suggested by Christie and Huang (1995), suggest the presence of herding in emerging markets such as South Korea and Taiwan, but failed to find evidence in the US, Hong Kong and Japanese markets.

However, our evidence is not consistent with the view that herding only happens when financial markets are in stress. On the contrary, figures 1 to 3 shows that herd behaviour can be detected when the markets are quiet. One possibility is that when the markets are under stress there may be other factors that replace the role of the market portfolio and serve as herding objectives and we test this hypothesis below. 
Another explanation is that the view that herding arises when financial markets are in stress may be simply wrong. When a market is in stress, we may observe large negative returns and the majority of the individual assets will also show negative returns. We tend to conclude that there is herding in the whole market. However, the dispersion of returns (cross-sectional variance of returns) is likely to be much larger during period of market stress than during quiet period. ${ }^{11}$ So even though the majority of assets show negative returns during market stress, the returns are more widely dispersed and hence herding may not in fact be present in such a period. The results in figures 1 to 3 support this argument, suggesting that herding during market stress may simply be an illusion and a common reaction to fundamental news.

In order to investigate if our finding of herding during quiet periods is dataspecific, we also used Christie and Huang's (1995) method for comparison. Their method requires the regression of the cross-sectional standard deviations (CX Stds) of individual stock returns on the two dummy variables; the first dummy variable, $D_{t}^{L}$, is set to one when the market returns lie in the extreme lower tail of the return distribution and to zero otherwise, and the second dummy variable, $D_{t}^{U}$, is set to one when the market returns lie in the extreme upper tail of the return distribution and to zero otherwise. The regression equation is

$$
S_{t}=\alpha+\beta_{1} D_{t}^{L}+\beta_{2} D_{t}^{U}+\epsilon_{t}
$$

where $S_{t}$ is the CX Std at time $t$

$$
S_{t}=\sqrt{\frac{\sum_{i=1}^{N}\left(r_{i t}-r_{m t}\right)^{2}}{N-1}}
$$

and

$$
r_{m t}=\frac{1}{N} \sum_{i=1}^{N} r_{i t}
$$

and $\epsilon_{t}$ is white noise.

They argue that rational asset pricing models predict significantly positive coefficients on the two dummy variables, whilst significantly negative coefficients represent the presence of herd behaviour. For the data in this study, we obtain the results in table 2, which can be compared with table 3 of Christie and Huang (1995) and are consistent in the sense that both sets of the results support their interpretation of rational asset pricing rather than the existence of herding. That is, we do not find any evidence of significantly negative coefficients for all three markets. As pointed out in Christie and Huang (1995) we also find that the increase in CX Stds is much

\footnotetext{
${ }^{11}$ Note that when time series volatility is large during market stress, cross-sectional volatility is also high (again see Hwang, 2000).
} 
more noticeable with extremely large positive returns rather than negative returnsexcept for the US market.

We note that we have 130 observations in our study and thus for the $1 \%$ extreme tail case we used only one observation and for the $5 \%$ extreme tail case, 7 observations were used to estimate the coefficients. Thus the results in table 2 (and also the results of Christie and Huang (1995) calculated with monthly data) are actually dependent on a very small number of observations. This indicates a further difficulty with the Christie and Huang approach.

\section{Herding toward Differing Factors}

As discussed above one of the important advantages of our approach is that we can measure herding towards other factors. In this subsection, we use multi-factor models to investigate herding towards the market, growth, value, and size factors in the US market. We also apply the same method to the South Korean market; herd behaviour toward the market returns and size factors.

We use exactly the same procedures as those in the previous subsection. That is, we use $\tau=60$ and roll the windows over time. For the four factor model for the US market, $\tau-K-2=55$ since $K=3$, and for the two factor model for the South Korean market, $\tau-K-2=57$ since $K=1$. Since the factor data in the US market are available only from January 1990 to March 1999, we have 111 observations for the US market. On the other hand for South Korea, size factor data are available from January 1990 to October 2000, which is the same period as used in the figures 1 to 3 .

Figures 4 and 5 report the herd statistics over time; figure 4 shows that measurements toward the market portfolio are smaller than those in Figure 1. This implies that the market factor is correlated with the other factors and when the other factors are considered, investors seem to be herding more toward the market portfolio. When there is relatively more herding toward the market returns, from early 1996 till July 1998, other factors do not seem to play a role as herd objectives. That is, during this period, the herd statistics for the other three factors do not show any significant change. However, during the Russian Crisis, the market portfolio did not play a pivotal role in herding, instead investors moved toward the value factor. The herd statistics toward the value factor show very similar patterns to those toward the growth factor until the Russian Crisis. However, around the Crisis, the estimated herd statistics toward the value factor have jumped from around 1 to more than 2.5 , both of which are significantly different from the average value of the estimated herding statistics. When there is a crisis, investors look for safe havens and thus value stocks are preferred to growth stocks.

This might be interpreted as fundamental adjustment based on rational decision 
making. However, as discussed above, any changes in fundamentals are reflected in factors such as value, growth, size and we would not expect a sudden change in the relationship between the factors and stock returns. In other words we would not expect a sudden change in the factor loadings. Again notice that this is actually different from observing changes in the returns themselves. These are possible and indeed natural and certainly do not imply any changes in relative factor loadings. Therefore, any sudden changes in our measures since the Russian Crisis can be interpreted as imitative herding rather than fundamental adjustments.

Another interesting feature of the new herd measure is that since the herd statistics toward factors beyond the market factor represent the cross-sectional standard deviation of the standardised coefficients (see equation (17)), the herd statistics indicate the relative importance between factors as well as over time. When we compare the three herd statistics for value, growth, and size factors, we find that the herd statistics toward size are larger and thus more important than those toward value and growth factors. However, as pointed earlier, the tendency toward risk aversion among investors puts the value factor in a more important position after the Russian Crisis.

For the South Korean market, we add only one additional factor, size, to the market model. Figure 5 still shows that herding toward the market returns disappears during the Asian Crisis in 1997. Since the correlation between the size factor and the market portfolio returns is close to zero, the estimated herding statistics towards the market portfolio in figure 5 are little different from those in figure 3. In addition, the estimated herd statistics towards size does not show a significant movement around the Asian Crisis. A similar phenomenon can be found in the US market; see figure 4. An interesting finding is that the estimated herding statistics towards the size in the South Korea market are far larger than those of the US market in figure 4, although they tend to decrease over time. This means that size is an important factor in South Korean market.

Summarising the empirical results of the various herd behaviours toward different factors and in the presence of different factors, we suggest that herding toward the market returns is more common when the market is relatively quiet rather than in stress. In addition, when the market is in stress, we observe herd behaviour towards value rather than growth. The size factor does not play an important role as a herd objective but seems to be more important than value and growth factors on average.

\section{Conclusions}

Herding is widely believed to be an important element of behaviour in financial markets and particularly when the market is in stress, such as during the Asian and Russian Crises of 1997 and 1998. In this study, we have proposed a new approach 
to measuring and testing herding. We argue that our measure has better empirical and theoretical properties than previous measures such as that proposed by Christie and Huang (1995) in the sense that the new measure conditions automatically on fundamentals and can also measure herding toward other factors. The new measure also accounts automatically for the influence of time series volatility.

We have applied our measure to the US, UK, and South Korean stock market and found that herding toward the market returns is heavily affected by the Asian and Russian Crises in 1997 and 1998. Contrary to common belief that herding is significant when the market is in stress, we find that herding can be more apparent before a crisis when the market is relatively quiet. Once a crisis appears herding toward the market returns becomes much weaker. Using multifactor models, we find again that when there is a crisis, value becomes more important than growth and size and plays a significant role as a herding objective. In addition, we also find that size is generally more important than value and growth. Our study also suggests that advanced markets such as the US and UK show less herd behaviour than emerging markets such as the South Korea. This may be explained by a larger information asymmetry between investors in emerging markets than in advanced markets. Finally, we find that a size factor in South Korean market has far more explanatory power than in the US and UK markets.

Clearly our empirical work has just scratched the surface of the potential application of the approach and more detailed analyses of herding attractors in different phases of market development now seem possible. This study has applied the new measure of herding to the market level. However, the measure can also be applied at a sector (industry) level and different herding behaviour may well be found in different sectors such as IT and old economy stocks. 


\section{References}

Banerjee, A. "A Simple Model of Herd Behavior." Quarterly Journal of Economics 107 (1992), 797-818.

Bekaert, G., C. B. Erb, C. R. Harvey, and T. E. Viskanta. "What Matters for Emerging Equity Market Investments." Emerging Markets Quarterly (1997), September, $17-46$.

Bikhchandani, S., D. Hirshleifer, and I. Welch. "A Theory of Fads, Fashion, Custom and Cultural Change as Informational Cascades." Journal of Political Economy 100 (1992), 992-1026.

Bikhchandani, S. and S. Sharma. "Herd Behavior in Financial Markets: A Review." IMF Working Paper WP/00/48 (2000).

Black, F. "Studies of Sock Market Volatility Changes." Proceedings of the American Statistical Association, Business and Economics Statistics Section (1976), 177-181. Brennan, M. "Agency and Asset Prices." Finance Working Paper No. 6-93 (1993), UCLA.

Campbell, J. Y., A. W. Lo, and A. C. MacKinlay. The Econometrics of Financial Markets. Princeton University Press (1997).

Chang, E. C., J. W. Cheng and A. Khorana. "An Examination of Herd Behavior in Equity Markets: An International Perspective." Journal of Banking and Finance 24(2000), 1651-1679.

Cho, Y. and R. F. Engle. "Time-Varying Betas and Asymmetric Effects of News: Empirical Analysis of Blue Chip Stocks." NBER Working Paper Series 7330 (1999). Cho, H., B. Kho, and R. M. Stulz. "Do Foreign Investors Destabilize Stock markets? The Korean Experience in 1997." Mimeo, Ohio State University (1999).

Christie, A. "The Stochastic Behaviour of Common Stock Variance: Value, Leverage and Interest Rate Effects." Journal of Financial Economics 10 (1982), 407-432.

Christie, W. G., and R. D. Huang. "Following the Pied Piper: Do Individual Returns Herd Around the Market?." Financial Analysts Journal (July-August 1995), 31-37. Connor, G. "A Unified Beta Pricing Theory." Journal of Economic Theory 34 (1984), 13-31.

Eichengreen, B., D. Mathieson, B. Chadha, L. Jansen, A. Kodres and S. Sharma. "Hedge Funds and Financial Market Dynamics." Occasional Paper No. 166 (1998), Washington: International Monetary Fund.

Fama, E. and K. R. French. "Common Risk factors in the Returns on Stocks and Bonds." Journal of Financial Economics 33 (1993), 3-56.

Ferson, W. E. and C. R. Harvey. "Predictability and Time-Varying Risk in World Equity Markets." Research in Finance 13 (1995), 25-88.

Hall, A., S. Hwang, and S. E. Satchell. "Using Bayesian Variable Selection Methods to Choose Style Factors in Global Stock Return Models." Forthcoming in Journal of Banking and Finance (2001). 
Hwang, S. "Properties of Cross-sectional Volatility." Financial Econometrics Research Centre working paper WP00-4, City University Business School (2000).

Hwang, S. and S. E. Satchell. "Improved Testing for the Efficiency of Asset Pricing Theories in Linear Factor Models." Financial Econometrics Research Centre working paper WP99-20, City University Business School (1999).

Hwang, S. and S. E. Satchell. "Valuing Information Using Utility Functions: How Much Should We Pay for Forecasts of Returns?" Financial Econometrics Research Centre working paper WP00-6, City University Business School (2000).

Kim, W. and S. Wei. "Offshore Investment Funds: Monsters in Emerging Markets." Working Paper No. 7133 (1999) (Cambridge, Massachusetts: NBER).

Lakonishok, J., A. Shleifer and R. W. Vishny. "The Impact of Institutional Trading on Stock Prices." Journal of Financial Economics 32 (1992), 23-43.

Roll, R. "A Mean Variance Analysis of Tracking Error." Journal of Portfolio Management Summer (1992), 13-22.

Scharfstein, D. and J. Stein. "Herd Behavior and Investment." American Economic Review 80 (1990), 465-479.

Shalit, H. and S. Yitzhaki. "Mean-Gini, Portfolio Theory and the Pricing of Risky Asset." Journal of Finance 39 (1984), 1449-1468.

Welch, I. "Sequential Sales, Learning and Cascades." Journal of Finance 47 (1992), 695-732.

Wermers, R. "Herding, Trade Reversals, and Cascading by Institutional Investors." mimeo, University of Colorado, Boulder (1995).

Yitzhaki, S. "Stochastic Dominance, Mean-variance, and Gini's Mean Difference." American Economic Review 72 (1982), 178-185. 
Table 1 Properties of Market Portfolio and Factor Returns

A. Properties of Monthly Factor Returns in the US Market

\begin{tabular}{|c|c|c|c|c|c|}
\hline Sample Period & & Mean & Standard Deviation & Skewness & Excess Kurtosis \\
\hline January 1990 - October 2000 & Market Excess Return & 0.871 & 4.366 & -0.710 & 1.997 \\
\hline \multirow[t]{10}{*}{ January 1990 -March 1999} & Market Excess Return & 1.006 & 4.360 & -0.922 & 2.677 \\
\hline & Value & 1.062 & 2.821 & -0.719 & 0.504 \\
\hline & Growth & -0.929 & 0.985 & -0.063 & 1.674 \\
\hline & Size & 1.533 & 2.529 & -0.878 & 1.600 \\
\hline & \multicolumn{5}{|c|}{ Correlation Matrix } \\
\hline & & Market Excess Return & Value & Growth & Size \\
\hline & Market Excess Return & 1.000 & & & \\
\hline & Value & -0.376 & 1.000 & & \\
\hline & Growth & 0.461 & -0.326 & 1.000 & \\
\hline & Size & -0.027 & -0.270 & 0.079 & 1.000 \\
\hline
\end{tabular}

\section{B. Properties of Monthly Factor Returns in the UK Market}

\begin{tabular}{|c|c|c|c|c|c|}
\hline Sample Period & & Mean & Standard Deviation & Skewness & Excess Kurtosis \\
\hline January 1990 - October 2000 & Market Excess Return & 0.604 & 4.655 & -0.473 & 0.897 \\
\hline
\end{tabular}

\section{Properties of Monthly Factor Returns in the South Korean Market}

\begin{tabular}{|c|c|c|c|c|c|}
\hline Sample Period & & Mean & Standard Deviation & Skewness & Excess Kurtosis \\
\hline \multirow[t]{5}{*}{ January 1990 - October 2000} & Market Excess Return & -1.432 & 10.119 & 0.314 & 2.198 \\
\hline & Size & -0.019 & 0.350 & 0.066 & 1.981 \\
\hline & \multicolumn{5}{|c|}{ Correlation Matrix } \\
\hline & & Market Excess Return & Size & & \\
\hline & $\begin{array}{c}\text { Market Excess Return } \\
\text { Size }\end{array}$ & $\begin{array}{l}1.000 \\
0.001\end{array}$ & 1.000 & & \\
\hline
\end{tabular}




\section{Table 2 Christie and Huang's (1995) Regression Test Results for Herd Behaviour}

\section{A. US Financial Market}

\begin{tabular}{|c|c|c|c|c|c|c|}
\hline & \multicolumn{3}{|c|}{ Extreme Tails Are Defined as $1 \%$ of the Market Portfolio Return Distribution } & \multicolumn{3}{|c|}{ Extreme Tails Are Defined as 5\% of the Market Portfolio Return Distribution } \\
\hline & Constant & Beta on Extreme Lower Tail & Beta on Extreme Upper Tail & Constant & Beta on Extreme Lower Tail & Beta on Extreme Upper Tail \\
\hline $\begin{array}{c}\text { Estimates } \\
\text { t-values }\end{array}$ & $\begin{array}{c}8.905 \\
(43.395)\end{array}$ & $\begin{array}{c}4.050 \\
(1.738)\end{array}$ & $\begin{array}{c}0.184 \\
(0.079)\end{array}$ & $\begin{array}{c}8.705 \\
(41.753)\end{array}$ & $\begin{array}{c}2.540 \\
(2.907)\end{array}$ & $\begin{array}{c}1.791 \\
(2.049)\end{array}$ \\
\hline
\end{tabular}

\section{B. UK Financial Market}

\begin{tabular}{|c|c|c|c|c|c|c|}
\hline & \multicolumn{3}{|c|}{ Extreme Tails Are Defined as $1 \%$ of the Market Portfolio Return Distribution } & \multicolumn{3}{|c|}{ Extreme Tails Are Defined as 5\% of the Market Portfolio Return Distribution } \\
\hline & Constant & Beta on Extreme Lower Tail & Beta on Extreme Upper Tail & Constant & Beta on Extreme Lower Tail & Beta on Extreme Upper Tail \\
\hline $\begin{array}{c}\text { Estimates } \\
\text { t-values }\end{array}$ & $\begin{array}{c}8.960 \\
(38.624) \\
\end{array}$ & $\begin{array}{c}0.770 \\
(0.292) \\
\end{array}$ & $\begin{array}{l}12.913 \\
(4.901) \\
\end{array}$ & $\begin{array}{c}8.873 \\
(34.529) \\
\end{array}$ & $\begin{array}{c}0.362 \\
(0.336)\end{array}$ & $\begin{array}{c}3.200 \\
(2.970) \\
\end{array}$ \\
\hline
\end{tabular}

\section{South Korean Financial Market}

\begin{tabular}{|c|c|c|c|c|c|c|}
\hline & \multicolumn{3}{|c|}{ Extreme Tails Are Defined as $1 \%$ of the Market Portfolio Return Distribution } & \multicolumn{3}{|c|}{ Extreme Tails Are Defined as 5\% of the Market Portfolio Return Distribution } \\
\hline & Constant & Beta on Extreme Lower Tail & Beta on Extreme Upper Tail & Constant & Beta on Extreme Lower Tail & Beta on Extreme Upper Tail \\
\hline $\begin{array}{c}\text { Estimates } \\
\text { t-values }\end{array}$ & $\begin{array}{c}11.846 \\
(26.580)\end{array}$ & $\begin{array}{c}3.568 \\
(0.705)\end{array}$ & $\begin{array}{l}10.884 \\
(2.150)\end{array}$ & $\begin{array}{l}11.300 \\
(25.548)\end{array}$ & $\begin{array}{c}5.242 \\
(2.827)\end{array}$ & $\begin{array}{c}6.974 \\
(3.761)\end{array}$ \\
\hline
\end{tabular}

Notes: Cross-sectional standard deviations were regressed on constant, and the two dummy variables; one represents if the market returns belong to the extreme lower tail and the other represents if the market return belong to the extreme upper tail of the return distribution. The total number of sample is 130 monthly returns from January 1990 to October 2000. 
Figure 1 US Herd Behaviour toward the Market Portfolio

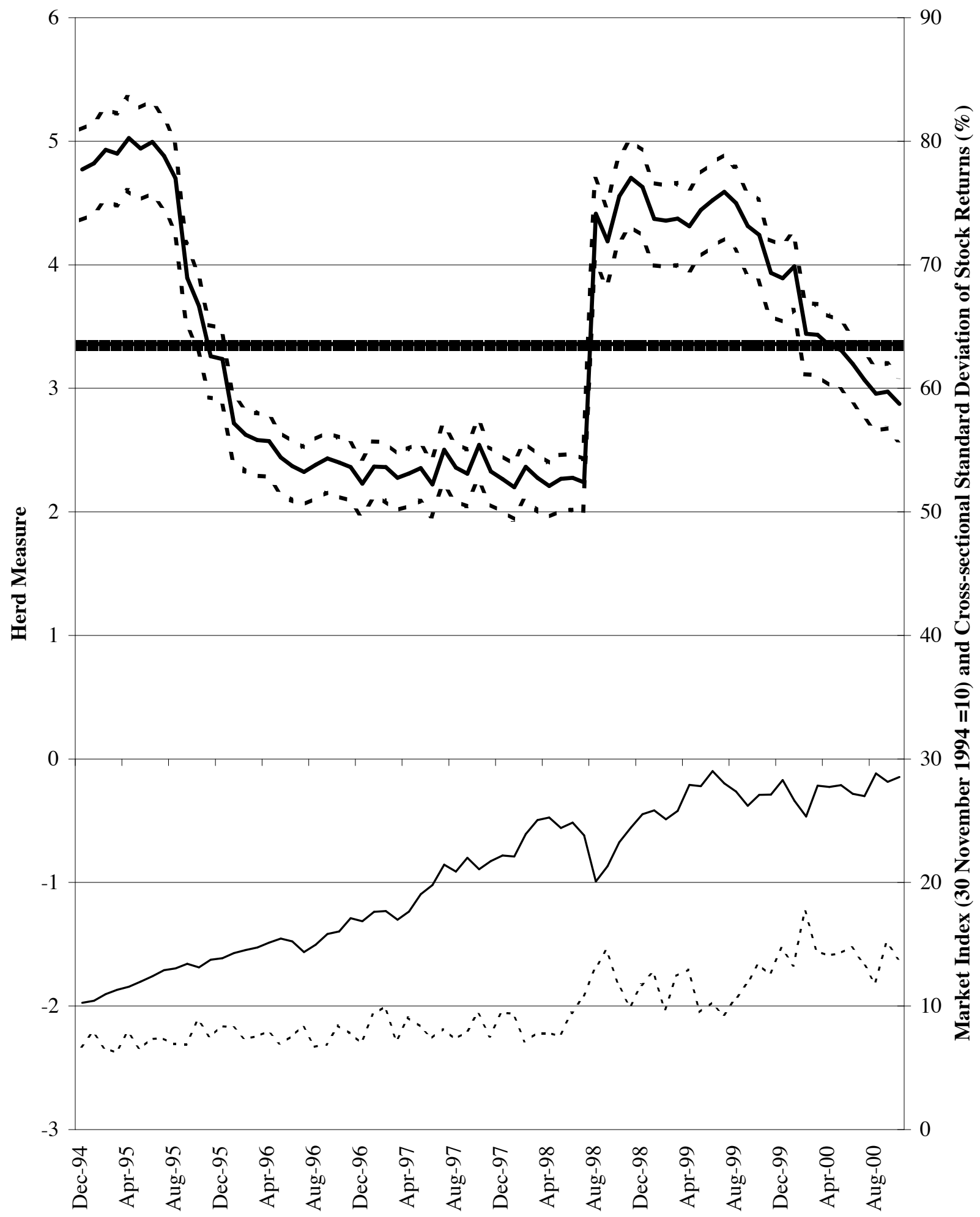


Figure 2 UK Herd Behaviour toward the Market Portfolio

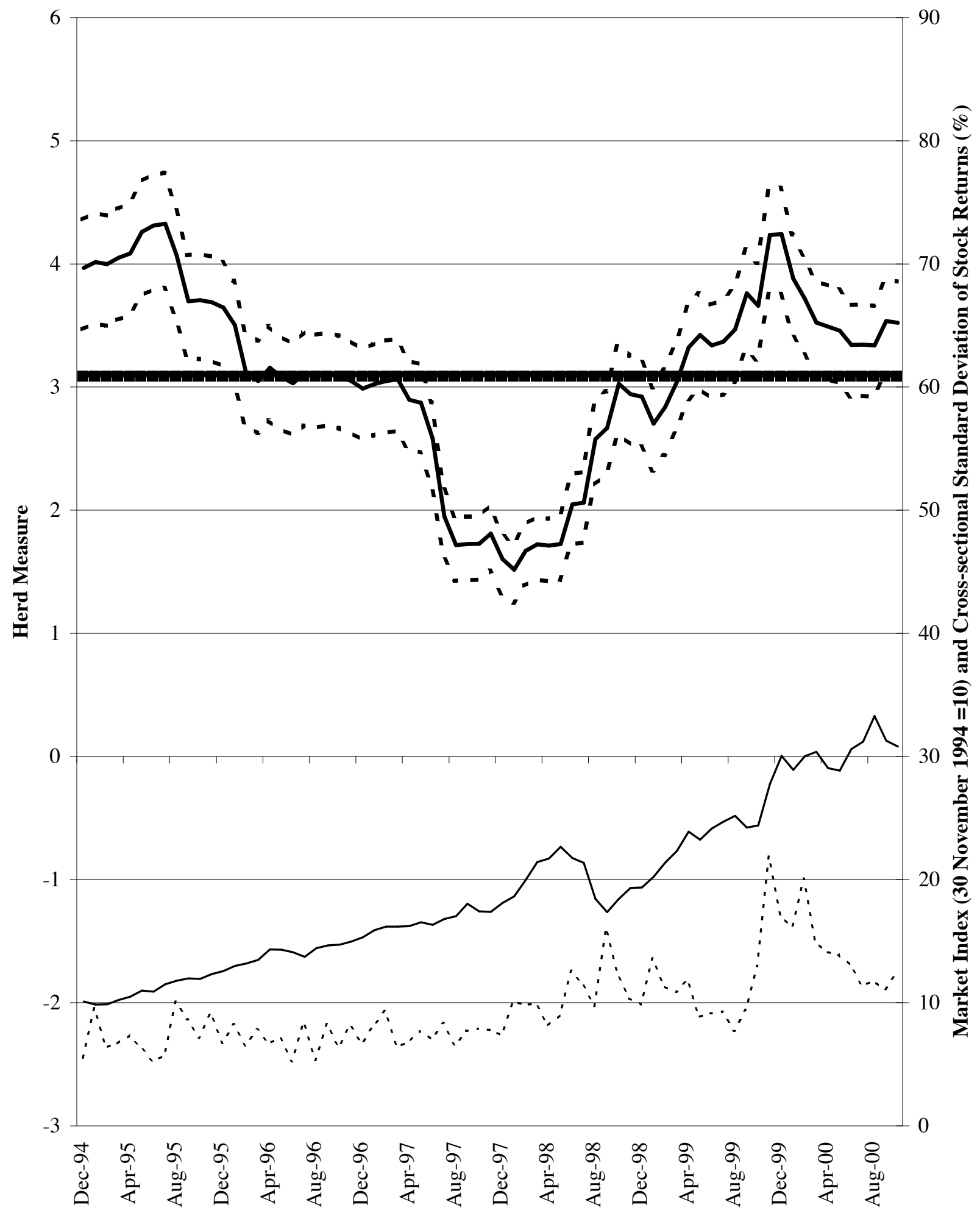




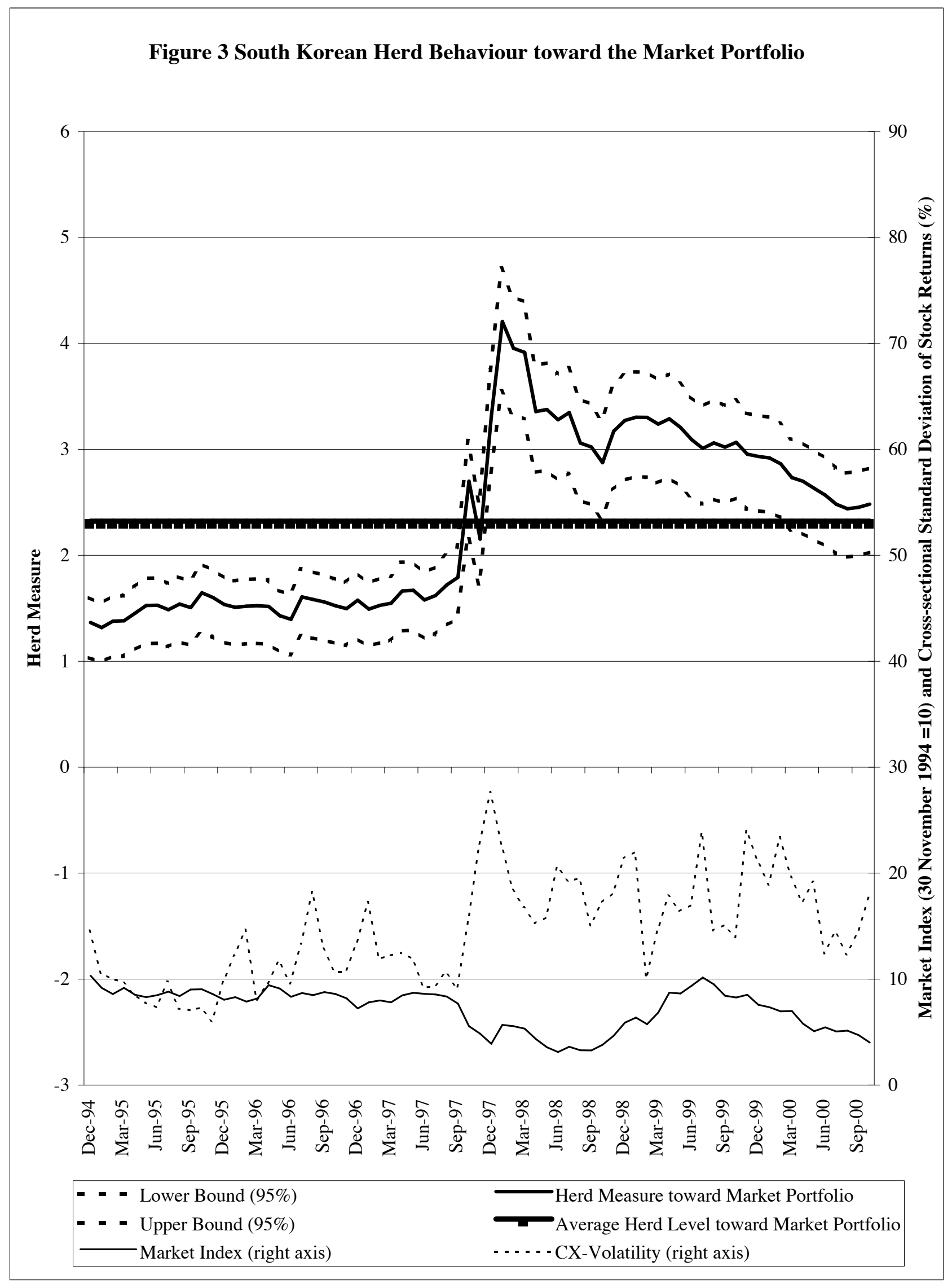


Figure 4 Herd Behaviour in the US Market toward the Market Portfolio, Value, Growth, and Size

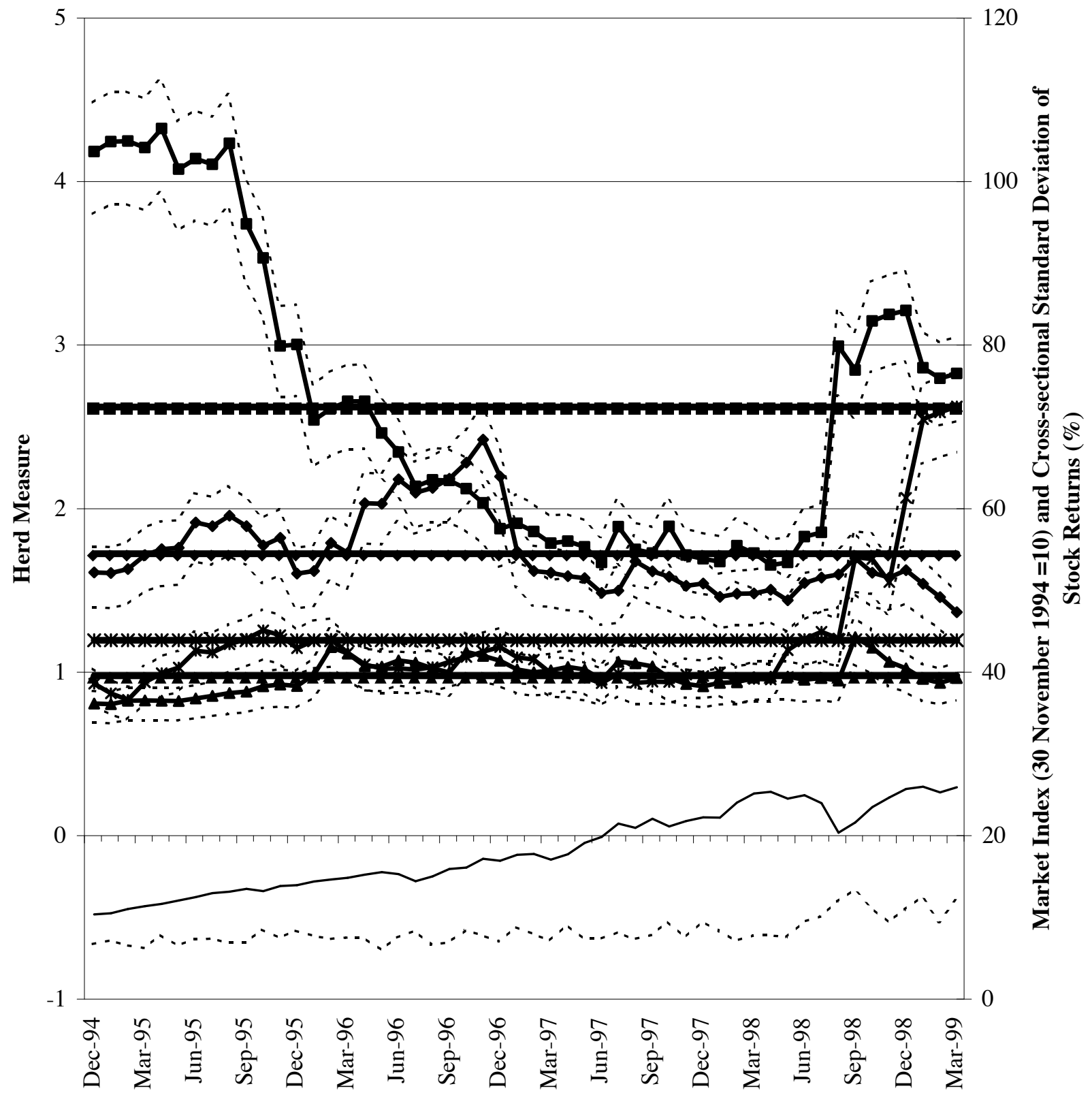

\begin{tabular}{|c|c|}
\hline - - - - Lower Bound (95\%) & $\longrightarrow$ Herd Measure toward Market Portfolio \\
\hline - - - - Upper Bound (95\%) & - - - - Lower Bound (95\%) \\
\hline$*$ Herd Measure toward Value & - - - - Upper Bound (95\%) \\
\hline - - - - - Lower Bound (95\%) & $\longrightarrow$ Herd Measure toward Growth \\
\hline - - - - - Upper Bound (95\%) & - - - - - Lower Bound (95\%) \\
\hline$\longrightarrow$ Herd Measure toward Size & - Upper Bound (95\%) \\
\hline Average Herd Level toward Market Portfolio & Average Herd Level toward Value \\
\hline Average Herd Level toward Growth & Average Herd Level toward Size \\
\hline$\longrightarrow$ Market Index (right axis) & - - - CX-Volatility (right axis) \\
\hline
\end{tabular}


Figure 5 Herd Behaviour in the South Korean Market toward the Market Portfolio and Size Factor
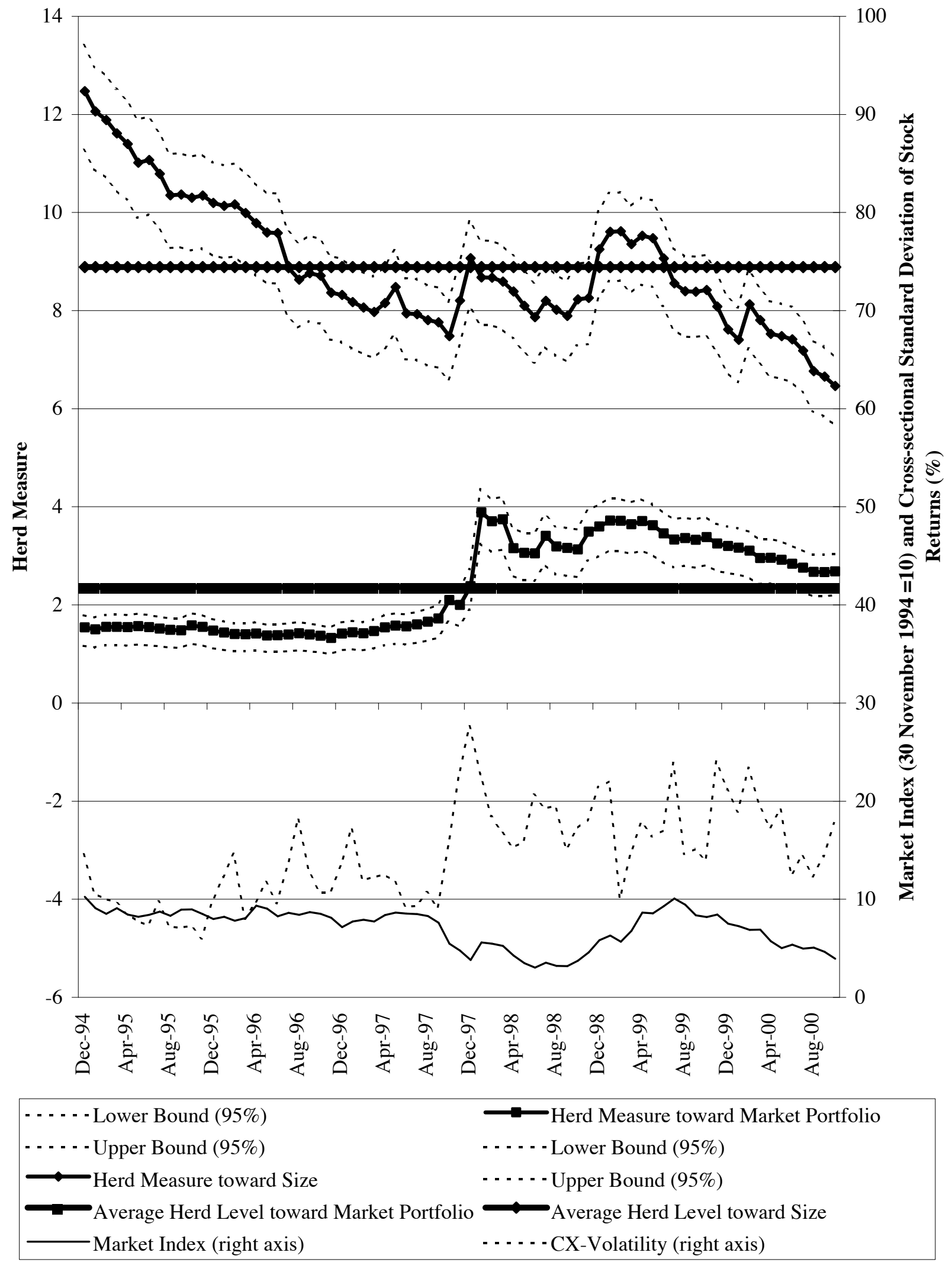


\section{List of other working papers:}

\section{1}

1. Soosung Hwang and Steve Satchell, GARCH Model with Cross-sectional Volatility; GARCHX Models, WP01-16

2. Soosung Hwang and Steve Satchell, Tracking Error: Ex-Ante versus Ex-Post Measures, WP01-15

3. Soosung Hwang and Steve Satchell, The Asset Allocation Decision in a Loss Aversion World, WP01-14

4. Soosung Hwang and Mark Salmon, An Analysis of Performance Measures Using Copulae, WP01-13

5. Soosung Hwang and Mark Salmon, A New Measure of Herding and Empirical Evidence, WP01-12

6. Richard Lewin and Steve Satchell, The Derivation of New Model of Equity Duration, WP0111

7. Massimiliano Marcellino and Mark Salmon, Robust Decision Theory and the Lucas Critique, WP01-10

8. Jerry Coakley, Ana-Maria Fuertes and Maria-Teresa Perez, Numerical Issues in Threshold Autoregressive Modelling of Time Series, WP01-09

9. Jerry Coakley, Ana-Maria Fuertes and Ron Smith, Small Sample Properties of Panel Timeseries Estimators with I(1) Errors, WP01-08

10. Jerry Coakley and Ana-Maria Fuertes, The Felsdtein-Horioka Puzzle is Not as Bad as You Think, WP01-07

11. Jerry Coakley and Ana-Maria Fuertes, Rethinking the Forward Premium Puzzle in a Nonlinear Framework, WP01-06

12. George Christodoulakis, Co-Volatility and Correlation Clustering: A Multivariate Correlated ARCH Framework, WP01-05

13. Frank Critchley, Paul Marriott and Mark Salmon, On Preferred Point Geometry in Statistics, WP01-04

14. Eric Bouyé and Nicolas Gaussel and Mark Salmon, Investigating Dynamic Dependence Using Copulae, WP01-03

15. Eric Bouyé, Multivariate Extremes at Work for Portfolio Risk Measurement, WP01-02

16. Erick Bouyé, Vado Durrleman, Ashkan Nikeghbali, Gael Riboulet and Thierry Roncalli, Copulas: an Open Field for Risk Management, WP01-01

\section{0}

1. Soosung Hwang and Steve Satchell, Valuing Information Using Utility Functions, WP00-06

2. Soosung Hwang, Properties of Cross-sectional Volatility, WP00-05

3. Soosung Hwang and Steve Satchell, Calculating the Miss-specification in Beta from Using a Proxy for the Market Portfolio, WP00-04

4. Laun Middleton and Stephen Satchell, Deriving the APT when the Number of Factors is Unknown, WP00-03

5. George A. Christodoulakis and Steve Satchell, Evolving Systems of Financial Returns: AutoRegressive Conditional Beta, WP00-02

6. Christian S. Pedersen and Stephen Satchell, Evaluating the Performance of Nearest Neighbour Algorithms when Forecasting US Industry Returns, WP00-01

1999

1. Yin-Wong Cheung, Menzie Chinn and Ian Marsh, How do UK-Based Foreign Exchange Dealers Think Their Market Operates?, WP99-21 
2. Soosung Hwang, John Knight and Stephen Satchell, Forecasting Volatility using LINEX Loss Functions, WP99-20

3. Soosung Hwang and Steve Satchell, Improved Testing for the Efficiency of Asset Pricing Theories in Linear Factor Models, WP99-19

4. Soosung Hwang and Stephen Satchell, The Disappearance of Style in the US Equity Market, WP99-18

5. Soosung Hwang and Stephen Satchell, Modelling Emerging Market Risk Premia Using Higher Moments, WP99-17

6. Soosung Hwang and Stephen Satchell, Market Risk and the Concept of Fundamental Volatility: Measuring Volatility Across Asset and Derivative Markets and Testing for the Impact of Derivatives Markets on Financial Markets, WP99-16

7. Soosung Hwang, The Effects of Systematic Sampling and Temporal Aggregation on Discrete Time Long Memory Processes and their Finite Sample Properties, WP99-15

8. Ronald MacDonald and Ian Marsh, Currency Spillovers and Tri-Polarity: a Simultaneous Model of the US Dollar, German Mark and Japanese Yen, WP99-14

9. Robert Hillman, Forecasting Inflation with a Non-linear Output Gap Model, WP99-13

10. Robert Hillman and Mark Salmon , From Market Micro-structure to Macro Fundamentals: is there Predictability in the Dollar-Deutsche Mark Exchange Rate?, WP99-12

11. Renzo Avesani, Giampiero Gallo and Mark Salmon, On the Evolution of Credibility and Flexible Exchange Rate Target Zones, WP99-11

12. Paul Marriott and Mark Salmon, An Introduction to Differential Geometry in Econometrics, WP99-10

13. Mark Dixon, Anthony Ledford and Paul Marriott, Finite Sample Inference for Extreme Value Distributions, WP99-09

14. Ian Marsh and David Power, A Panel-Based Investigation into the Relationship Between Stock Prices and Dividends, WP99-08

15. Ian Marsh, An Analysis of the Performance of European Foreign Exchange Forecasters, WP99-07

16. Frank Critchley, Paul Marriott and Mark Salmon, An Elementary Account of Amari's Expected Geometry, WP99-06

17. Demos Tambakis and Anne-Sophie Van Royen, Bootstrap Predictability of Daily Exchange Rates in ARMA Models, WP99-05

18. Christopher Neely and Paul Weller, Technical Analysis and Central Bank Intervention, WP9904

19. Christopher Neely and Paul Weller, Predictability in International Asset Returns: A Reexamination, WP99-03

20. Christopher Neely and Paul Weller, Intraday Technical Trading in the Foreign Exchange Market, WP99-02

21. Anthony Hall, Soosung Hwang and Stephen Satchell, Using Bayesian Variable Selection Methods to Choose Style Factors in Global Stock Return Models, WP99-01

\section{8}

1. Soosung Hwang and Stephen Satchell, Implied Volatility Forecasting: A Compaison of Different Procedures Including Fractionally Integrated Models with Applications to UK Equity Options, WP98-05

2. Roy Batchelor and David Peel, Rationality Testing under Asymmetric Loss, WP98-04

3. Roy Batchelor, Forecasting T-Bill Yields: Accuracy versus Profitability, WP98-03

4. Adam Kurpiel and Thierry Roncalli, Option Hedging with Stochastic Volatility, WP98-02

5. Adam Kurpiel and Thierry Roncalli, Hopscotch Methods for Two State Financial Models, WP98-01 